\title{
MEASURED RESPONSE OF THE EQUATORIAL THERMOSPHERIC TEMPERATURE TO GEOMAGNETIC ACTIVITY AND
} SOLAR FLUX CHANGES

\author{
Manfred A. Biondi ${ }^{1}$ and John W. Meriwether, Jr. ${ }^{2}$
}

${ }^{1}$ Dept. of Physics and Astronomy, University of Pittsburgh, Pittsburgh, Pennsylvania 15260

${ }^{2}$ Space Physics Research Laboratory, University of Michigan, Ann Arbor, Michigan 48109

Abstract. Fabry-Perot interferometer determinations of thermospheric temperatures from 630.0 $\mathrm{nm}$ nightglow line width measurements have been carried out for the period April-August 1983 from Arequipa, Peru $\left(16.4^{\circ} \mathrm{S}, 71.5^{\circ} \mathrm{W}\right.$ geographic; $4.4^{\circ} \mathrm{S}$ magnetic). The nightly variation of the thermospheric temperature $T_{n}$ measured on 62 nights is compared with MSIS model predictions and found to agree occasionally with the model but, on average, to exceed model predictions by $\sim 180 \mathrm{~K}$. The largest differences, 400-500 $\mathrm{K}$, of ten occur during strongly increasing geomagnetic activity such as sudden commencements. The rapid increases in $T_{n}$ may result from energetic neutrals precipitating at low latitudes from the ring current or from energy carried to equatorial regions from highlatitude (auroral ova1) heat sources by gravity waves and equatorward neutral winds.

\section{Introduction}

The temperature of the neutral thermosphere has been monitored by various ground-based and satellite techniques wich include direct determinations such as measurements of the doppler width of the $630.0 \mathrm{~nm}$ airglow line and indirect methods such as radar backscatter plasma measurements and satellite $\mathrm{N}_{2}$ scale height and orbit decay observations (see, for example, Jacchia, 1977; Hedin et al., 1977; Thuillier et al., 1977; Hernandez, 1982; Sipler, et al., 1983 and the references cited therein). The temperature is expected to change in response to changing energy inputs in the heat balance equation governing the neutral thermosphere, in particular, to changes in the fluxes of solar radiation and of precipitating particles which are stopped in the upper atmosphere. A number of semi-empirical models (e.g., Jacchia, 1977; Hedin et a1., 1977; Thuillier et a1., 1977; Hernandez, 1982; Hedin, 1983) predict thermospheric temperatures on the basis of indices related to solar uv and high-latitude precipitating particle fluxes, e.g., $F_{10}, K_{p}$ or $A_{p}$, etc. However, the measured diurnal variations and responses during geomagnetic storm conditions of ten are rather different from the predicted behavior.

Recently, an automated airglow observatory has been set up at Arequipa, Peru $\left(16.4^{\circ} \mathrm{S}, 71.5^{\circ} \mathrm{W}\right.$ geographic, $4.4^{\circ} \mathrm{S}$ geomagnetic) in a joint effort by the Universities of Pittsburgh and Michigan, with the cooperation of the personnel of the NASA Satellite Tracking Station at Arequipa. The principal observatory instrument is a field-widened 100 $\mathrm{mm}$ aperture Fabry-Perot interferometer suitable

Copyright 1985 by the American Geophysical Union.

Paper number 5L 6499 .

0094-8276/85/004L-6499\$03.00 for nightglow $630.0 \mathrm{~nm}$ doppler width and doppler shift determinations. The unusually clear weather at Arequipa permits nightglow measurements on many successive nights, yielding sequences of $\sim 12$ hour measurements of nighttime temperatures which detail the short-term response of the thermosphere to changing solar euv radiation and geomagnetic activity.

\section{Apparatus}

The optical apparatus and its electronic control hardware are very similar to those described in detail by Sipler et al. (1983), while the computer control and data acquisition system and its software are of the type described by Meriwether et a1. (1983). The system provides for automatic observations of the $630.0 \mathrm{~nm}$ nightglow line by the Fabry-Perot (F-P) interferometer and a tilting filter photometer which monitors the wavelength range $628-631 \mathrm{~nm}$ in order to detect interfering radiation (e.g., from $\mathrm{OH}$ ) and cloud effects on the $630.0 \mathrm{~nm}$ observations. The common lines-of-sight of the two instruments are directed to the desired point in the sky by a two-axis pointing head on the roof of the observatory building. The estimated error in the neutral temperatures determined from the $630.0 \mathrm{~nm}$ line widths varies with the nightglow intensity, ranging from $\pm 40 \mathrm{~K}$ to \pm 150 $\mathrm{K}$ in most cases.

\section{Results}

Examples of the neutral temperatures $T_{n}$ determined from the $630.0 \mathrm{~nm}$ doppler widths are given in Fig. 1, which presents data during both a geomagnetically active period in June and a quiet period in August. In order to display all 62 nights of data together with suitable solar and geomagnetic activity indices in a reasonably compact form, we have averaged the $T_{n}$ values over each full cycle of observing directions (e.g., $N$, $E, S, W)$ and plotted the resulting point as an $x$ in Fig. 2, thus displaying the measured temperature range on a given night.

\section{Discussion and Conclusions}

The principal findings of these equatorial thermospheric temperature measurements relate to: (a) substantial differences between the interferometrically determined nighttime $T_{n}$ values, on average, and those given by the MSIS model and (b) the rapid ( $\lesssim 1$ day delay) and large increase in $T_{n}$ which frequently follows sudden increases in geomagnetic activity. It is clear from Figs. 1 and 2 that, while there are some nights when the $T_{n}$ values deduced from the $630.0 \mathrm{~nm}$ line width measurements agree reasonably with the MSIS model predictions, e.g., during August, many of the mea- 


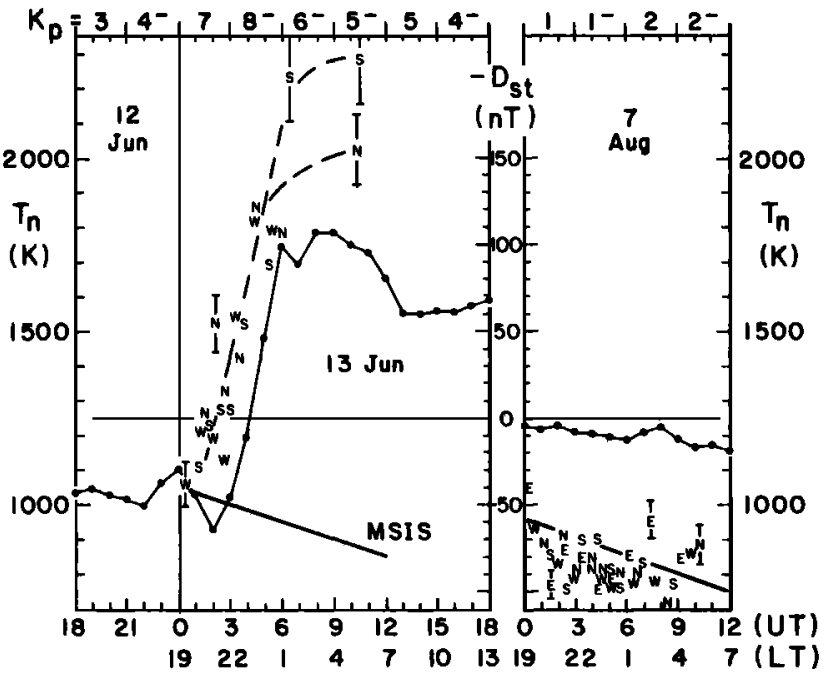

Fig. 1. Nightime thermospheric temperatures $T_{n}$ measured during the geomagnetic storm of 13 June $1983\left(\Sigma \mathrm{K}_{\mathrm{p}}=42^{+}, \mathrm{A}_{\mathrm{p}}=70\right)$ and during the quiet day 7 August $1983\left(\Sigma K_{\mathrm{p}}=20, \mathrm{~A}_{\mathrm{p}}=18\right)$. The symbols $N, S, E, W$ represent observing azimuths, the dots, - $\mathrm{D}_{\mathrm{st}}$ values. The straight solid lines are the MSIS mode1 predictions.

surements yield temperatures significantly higher $(100 \mathrm{~K}-500 \mathrm{~K})$ than the predicted values. We have been unable to find any instrumental effect which can account for erroneously high temperatures of significant magnitude. Non-thermal broadening of the $630.0 \mathrm{~nm}$ nightglow line by some remnants of the dissociation kinetic energy from the electron-ion recombination which produces the $O\left({ }^{1} D\right)$ atoms or kinetic energy of precipitating energetic oxygen atoms (Torr and Torr, 1984) can not account for the elevated measured temperatures. In the former case, at the expected emission altitudes $(<350 \mathrm{~km})$, the excited atoms should be slowed by collisions before radiation occurs, while in the latter, the relatively few energetic 0 atoms would have to share their kinetic energy with and simultaneous1y excite the ambient 0 atoms to the $1_{D}$ state in order to have a discernible effect near the doppler core of the line.
Significant differences between measured $T_{n}$ values and MSIS predictions occur both during periods of high solar/low geomagnetic activity, e.g., June 3-7, and during periods of low solar/high geomagnetic activity, e.g., Apri1 2-16. Thus, the prediction by the MSIS model of lower-than-measured exospheric temperatures can not be traced to an incorrect dependence on one activity index (solar or geomagnetic) alone.

Our measurements of equatorial thermospheric temperatures over Kwajalein Atoll during August and September 1977 (Sipler et al., 1983) also yielded higher values, on the average, (by $\sim 330 \mathrm{~K}$ ) than the MSIS model predictions. In addition, Hernandez (1982) has analyzed the $T_{\mathfrak{n}}$ values he obtained from $630.0 \mathrm{~nm}$ nightglow line width measurements at midlatitude (Fritz Peak Observatory, Colorado) from 1972 to 1979 and finds that his measured values exceed the MSIS model predictions by an average of $100-150 \mathrm{~K}$. The measured values in Fig. 2 exceed the MSIS model predictions by $\sim 180 \mathrm{~K}$ on the average, so that substantial differences between values of $T_{n}$ determined by ground-based F-P's and those of the MSIS model seem to be a problem at both mid- and equatorial latitudes.

Since the MSIS models involve empirical fits of a $T_{n}$ data base (derived from incoherent scatter and in-situ mass spectrometer measurements) to solar and geomagnetic indices, intercomparison of the $T_{n}$ values detexmined by $F-P$, incoherent scatter and mass spectrometer techniques might suggest the source of the discrepancy between our measured $T_{n}$ values and the MSIS predictions. Simultaneous F-P and incoherent scatter determinations reported in two papers (Cogger et al., 1970 and Hernandez et al., 1975) revealed only small differences, $\delta 30 \mathrm{~K}$, in the $\mathrm{T}_{\mathrm{n}}$ 's determined by the two techniques; therefore, the F-P measurements should be in agreement with one element of the MSIS data base. Perhaps the assumption of hydrostatic equilibrium in scale height analyses of satellite/rocket $\mathrm{N}_{2}$ density profiles leads to inference of low values of $T_{n}$ for this part of the MSIS data base, thereby accounting for the low values predicted by the empirical model.

Turning to the short-term response ( $\therefore 1$ day) of the thermospheric temperature to rapid changes in energy deposition by particle precipitation or by solar euv, we have attempted to indicate chang-
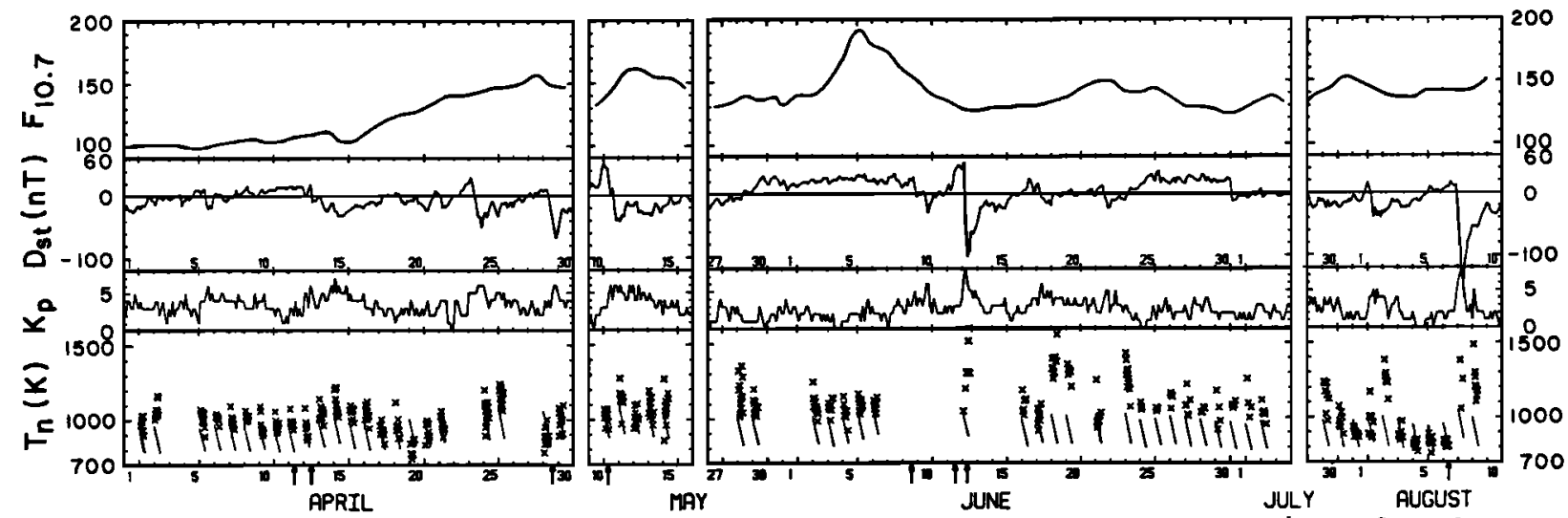

Fig. 2. Summary of the $\mathrm{T}_{\mathrm{n}}$ nighttime measurements as a function of Universal Time/Date from 2 April9 August 1983; the $\mathrm{x}$ symbols are the azimuth-averaged data (see text); the solid lines, the MSIS model predictions. Also shown are $\mathrm{F}_{10.7}, \mathrm{D}_{\mathrm{st}}$ and $\mathrm{K}_{\mathrm{p}}$ values. The arrows indicate sudden commencements. 
ing thermospheric conditions by including the $\mathrm{K}_{\mathrm{p}}$ and $D_{s t}$ values in Figs. 1 and 2 , as well as the $\mathrm{F}_{10.7}$ values in Fig. 2. Since the semiempirical models such as MSIS or those of Jacchia are intended to describe longer term behavior of the thermosphere, it is not surprising that our finding of rapid responses of $\mathrm{T}_{\mathrm{n}}$ to strongly increased geomagnetic activity, especially sudden commencements, (see Fig. 2) is not reflected in the MSIS model predictions for those periods.

If large energy inputs to the thermosphere via particle precipitation are signalled by a substantial increase in $K_{p}$ and/or negative change in $D_{s t}$, the temperature surges in the observations summarized in Fig. 2 appear to fall into three categories: 1) Very large and prompt increases in $T_{n}$, delayed by a few hours or less following large changes in both indices (e.g., 13 June and 8 August); 2) Large elevations in $T_{n}$ approximately a day after substantial changes in the indices (1112 May and 2-3 August); 3) Large elevations in $T_{n}$ during relatively quiet geomagnetic periods (2930 May, 19-20 June, 24 June). In this paper we discuss in detail only the first of these categories, as illustrated by the 13 June data of Fig. 1, which includes for comparison the geomagnetically quiet day 7 August.

Following sudden commencements on both 12 and 13 June, $K_{p}$ rose to a peak value of $8^{-}$and $D_{s t}$ changed from $+64 \mathrm{nT}$ to $-99 \mathrm{nT}$ in a four hour period. During this same period, $\mathrm{T}_{\mathrm{n}}$ rose from a "base" temperature of 1050-1150 $\mathrm{K}$ to $1800-2200 \mathrm{~K}$, with essentially no delay relative to the large $D_{\text {st }}$ transient. During the geomagnetic storm of 21 February 1979 Hernandez et al. (1982) noted a very similar, if somewhat smaller, rise in $T_{n}\left(\Delta T_{n}\right.$ $\sim 600 \mathrm{~K}$ for $\Delta \mathrm{D}_{\mathrm{st}} \sim-95 \mathrm{nT}$ in four hours) in their south-directed observations from their midlatitude observatory at Fritz Peak, Colorado, with little delay ( $\leq 1$ hour) in the S-, E- and $\mathrm{W}-\mathrm{di}-$ rected observations and perhaps a 4 hour delay in the $\mathrm{N}$-directed observation of the temperature rise. In both the equatorial and the midlatitude observations, the $\left(\Delta \mathrm{T}_{\mathbf{n}} / \Delta \mathrm{D}_{\mathbf{s t}}\right)$ ratio is similar, $\sim-6 \mathrm{~K} / \mathrm{nT}$.

The largest prompt responses of $T_{n}$ were to the south (poleward) of the near-equatorial Arequipa observatory and to the south (equatorward) of the mid-1atitude Fritz Peak observatory, suggesting that in both cases the energy source for the rapid thermospheric heating was at an intermediate (low) latitude. The behavior of the meridional wind supports this suggestion, since over Arequipa a small ( $\leqslant 20 \mathrm{~m} / \mathrm{s}$ ) northward wind was observed until $\sim 03^{\mathrm{h}} \mathrm{UT}$, which increased when the large $D_{s t}$ transient occurred, to $\sim 100 \mathrm{~m} / \mathrm{s}$ northward by $05 \mathrm{~h}$ UT. Similarly, the Fritz Peak data show the wind to the south of the observatory increasing sharply, from $\pm 20 \mathrm{~m} / \mathrm{s}$ to $\sim 250 \mathrm{~m} / \mathrm{s}$ northward during the Dst transient, in spite of the large southward surge seen to the north, which reached $\sim 500 \mathrm{~m} / \mathrm{s}$ at the same time (due to high latitude heating).

These observations are consistent with the hypothesis of Tinsley (1979) that the net gain in energetic ions in the ring current, signalled by the large negative change in $\mathrm{D}_{\mathrm{st}}$, leads to a large flux of energetic neutrals (produced by ion-atom charge transfer from the magnetosphere into the thermosphere at a low magnetic latitude. However, it is difficult to account for the very large increases in $T_{n}$ that we observe, perhaps suggesting the need for rather localized energy deposition.

Finally, the several observations of a substantial rise in $\mathrm{T}_{\mathrm{n}}$ which occur up to a day after the geomagnetic indices show marked changes (the second category alluded to earlier) may result from gravity wave propagation of energy from a high latitude heating source to low latitudes. For example, recent calculations by Mayr et al. (1984) have indicated substantial elevation of exospheric temperatures at equatorial latitudes, $\Delta T_{n} / T_{n o} \sim 0.2$, several hours after the onset of Joule heating in the northern auroral oval. Such efficient and rapid propagation of energy may well be the source of the occasional, slightly delayed response of the low-latitude thermosphere to surges in high latitude heating. Also, equatorward winds driven by Joule heating in both the North and South auroral ovals and averaging 100$200 \mathrm{~m} / \mathrm{s}$ would cause compressional heating of the equatorial thermosphere about a day after the onset. Fejer et al. (1983) have attributed observed changes in the vertical drifts of the equatorial F-region over Jimarca, Peru, which occur about one day after the onset of some geomagnetic storms, to similar changes in the thermospheric circulation pattern. The third category of observations - those in which neither marked solar flux nor geomagnetic index changes signal the observed, substantial rises in $\mathrm{T}_{\mathrm{n}}$ - seems to belong to the same "unexplained" category as strong convergence or divergence in the thermospheric winds during geomagnetically quiet periods (see, for example, Sipler et al., 1983). The observations at Arequipa are continuing, with a view to obtaining more data concerning these abrupt increases in $T_{n}$ to elucidate the nature and location of the heating sources.

Acknowledgements. The authors are greatly indebted to J. Moody, who reduced the data tapes of the Arequipa observations, and to B. Kennedy, L. Slider, and C. Tepley, who contributed importantly to the set up of the observatory. Thanks are also due to NASA and to the Smithsonian Astrophysics Observatory for making available the observatory site at the Laser Satellite Tracking Station and to the station personnel, particularly D. Hallenbeck and T. Muszynski, for their assistance in setting up and maintaining the apparatus. We are grateful to A. Hedin for providing the MSIS model predictions and to $\mathrm{H}$. Mayr for making available the gravity wave results prior to publication. This research was supported, in part, by the Division of Atmospheric Sciences, National Science Foundation under Grant ATM-8121723 to the University of Pittsburgh and Grant ATM-8202440 to the University of Michigan and by NASA Grant NAG5-615 to the University of Michigan.

\section{References}

Cogger, L. L., G. J. Nelson, M. A. Biondi, R. D. Hake and D. P. Sipler, Coincident F-region temperature determinations from incoherent backscatter and doppler broadening of [0I] 6300 A, J. Geophys. Res., 75, 4887-4889, 1970.

Dickinson, R. E., E. C. Ridley and R. G. Roble, A three-dimensional general circulation model of the thermosphere, J. Geophys. Res., 86, 1499-1512, 1981. 
Fejer, B. G., M. F. Larsen and D. T. Farley, Equatorial disturbance dynamo electric fields, Geophys. Res. Letts., 10, 537-540, 1983.

Hedin, A. E., A revised thermospheric model based on mass spectrometer and incoherent scatter data: MSIS-83, J. Geophys. Res., 88, 10,170$10,188,1983$.

Hedin, A. E., J. E. Salah, J. V. Evans, C. W. Reber, G. P. Newton, N. W. Spencer, D. C. Kayser, D. Alcayde, P. Bauer, L. L. Cogger and J. P. McClure, A global thermospheric mode1 based on mass spectrometer and incoherent scatter data: MSIS 1. $\mathbf{N}_{2}$ density and temperature, J. Geophys. Res., 82, 2139-2147, 1977.

Hernandez, G., Midlatitude thermospheric neutral kinetic temperatures 1 . Solar, geomagnetic and long-term effects, J. Geophys. Res., 87, $1623-1632,1982$.

Hernandez, G., T. E. van Zandt, V. L. Peterson and J. P. Turtle, Comparison of optical and incoherent scatter measurements of nighttime exospheric temperature at the magnetic equator, J. Geophys. Res., 80, 3271-3274, 1975.

Hernandez, G., R. G. Roble, E. C. Ridley and J. H. Allen, Thermospheric response observed over Fritz Peak, Colorado during two large geomagnetic storms near solar cycle maximum, J. Geophys. Res. 87, 9181-9192, 1982.

Jacchia, L. G., Thermospheric temperature, density and composition: New Models, Spec. Rep. 375, Smithson. Astrophys. Obs., Cambridge, MA, 1977.

Mayr, H. G., I. Harris, F. Varosi and F. A. Herrero, Global excitation of wave phenomena in a dissipative multiconstituent medium, J. Geophys. Res., 89, 10929-10986, 1984.
Meriwether, J. W., C. A. Tepley, S. A. Price, P. B. Hays and L. L. Cogger, Remote ground-based observations of terrestrial airglow emissions and thermospheric dynamics at Calgary, Alberta, Canada, Optical Engineering, 22, 128-131, 1983.

Sipler, D. P., M. A. Biondi and R. G. Roble, Fregion neutral winds and temperatures at equatorial latitudes: Measured and predicted behavior during geomagnetically quiet conditions, Planet. Space Sci. , 31, 53-66, 1983.

Thuillier, G., J. L. Falin and C. Wachtel, Experimental global model of the exospheric temperature based on measurements from the FabryPerot interferometer on board the OGO-6 satellite - discussion of the data and properties of the model, J. Atmos. Terr. Phys., 39, 399-414, 1977.

Tinsley, B. A., Energetic neutral atom precipitation as a possible source of midlatitude Fregion winds, Geophys. Res. Lett. 6, 291-293, 1979.

Torr, M. R. and D. G. Torr, Energetic oxygen in a mid-1atitude aurora, J. Geophys. Res., 89, 5547-5553, 1984.

Wickwar, V., J. W. Meriwether, P. B. Hays and A. F. Nagy, The meridional thermospheric neutral wind measured by radar and optical techniques in the auroral region, J. Geophys. Res., 89, $10,987-10,998,1984$.

(Received March 5, 1985; accepted March 27, 1985.) 